\title{
PERANCANGAN SISTEM TELE-NAVIGATION PADA PESAWAT TANPA AWAK (MICRO UAV)
}

\author{
Agus Basukesti \\ Sekolah Tinggi Teknologi Adisutjipto \\ Email: Agus_basukesti@yahoo.com
}

\begin{abstract}
ABSTRAK
Sistem navigasi pada pengoperasian pesawat tanpa awak (Micro UAV) saat ini terdapat 2 cara yaitu dengan cara pandangan manual (line of sight) dan sistem autopilot. Sistem navigasi line of sight memiliki kelemahan jangkauan pesawat tanpa awak hanya pada radius 200 meter karena keterbatasan penglihatan dari pengendali. Metode autopilot adalah metode kendali pesawat dengan algoritma lock position and homing. Sistem autopilot bekerja dengan cara mencari koordinat posisi yang dituju kemudian kembali ke lokasi awal. Keunggulan teknologi ini adalah pesawat dapat menjangkau jarak yang cukup jauh. Akan tetapi metode ini memiliki kelemahan yaitu pesawat harus terbang tinggi dan pesawat belum bisa menghindari halangan seperti gedung pencakar langit maupun pepohonan tinggi. Dalam penelitian ini dirancang sebuah sistem tele-navigasi yang merupakan modifikasi sistem navigasi line of sight dan autopilot sehingga dapat menutupi kelemahan dari masing masing metode navigasi yang ada saat ini. metode penelitian yang digunakan dalam penelitian ini adalah metode eksperimen yaitu dengan membuat pilot plan sistem Tele-navigasi yang selanjutnya akan diuji dengan pesawat tanpa awak (micro UAV) jenis flying wing. Metode dokumentasi dan metode studi pustaka juga digunakan untuk melengkapi data teknis alat yang digunakan sehingga dapat dilakukan analisis mendalam terhadap performa alat yang dirancang.
\end{abstract}

Kata kunci: line of sight, lock position and homing, autopilot, micro UAV.

\begin{abstract}
The navigation system on the operation of unmanned aircraft (Micro UAV) currently there are 2 ways to view the manual way (line of sight) and autopilot systems. The navigation system has a line of sight range drone weakness only in a radius of 200 meters due to the limitations of vision of the controller. The method is a method of control of the aircraft autopilot to lock position and homing algorithm. Autopilot system works by looking for the coordinates of the target position and then back to the starting location. The advantages of this technology is the aircraft can reach a considerable distance. However, this method has the disadvantage of high-flying aircraft and aircraft should not be able to avoid obstacles such as skyscrapers and tall trees. In this study designed a tele-navigation system which is a modification of the navigation system and autopilot line of sight so as to cover the weaknesses of each navigation method available today. research methods used in this study is the experimental method is to create a pilot plan Tele-navigation system will then be tested with a drone (micro UAVs) flying wing type. Methods of documentation and library research methods are also used to complement the technical data used tool that can be performed in-depth analysis of the performance of the tool designed.
\end{abstract}

Keywords: line of sight, lock position and homing, autopilot, micro UAVs.

\section{PENDAHULUAN}

Pesawat tanpa awak merupakan salah satu topik penelitian yang sedang booming dalam 10 tahun terakhir. Aplikasi pesawat tanpa awak telah banyak digunakan dalam kehidupan seperti fungsi pengintaian pada militer, aerial photography bahkan untuk pembuatan film. Bisnis aerial photography dan video udara mulai berkembang seiring dengan semakin murahnya operasional pesawat tanpa awak dalam bisnis tersebut.

Sistem navigasi pada pengoperasian pesawat tanpa awak (mikro UAV) saat ini terdapat 2 cara yaitu dengan cara pandangan manual (line of sight) dan sistem autopilot. Metode line of sight adalah metode navigasi pesawat dimana pengendali pesawat dapat melakukan kendali dengan mata telanjang. Sistem navigasi line of sight memiliki kelemahan jangkauan pesawat tanpa awak hanya pada radius 200 meter karena keterbatasan penglihatan dari pengendali. Metode autopilot adalah metode kendali pesawat dengan algoritma lock position and homing. Sistem autopilot bekerja dengan cara mencari koordinat 
posisi yang dituju kemudian kembali ke lokasi awal. Keunggulan teknologi ini adalah pesawat dapat menjangkau jarak yang cukup jauh. Akan tetapi metode ini memiliki kelemahan yaitu pesawat harus terbang tinggi dan pesawat belum bisa menghindari halangan seperti gedung pencakar langit maupun pepohonan tinggi.

Dalam penelitian ini penulis tertarik mengembangkan sistem navigasi yang menggabungkan keunggulan kedua metode navigasi yang sudah ada untuk mengatasi kelemahan dari masing masing sistem. Teknologi tele-navigasi adalah teknologi navigasi pesawat yang berada di ground station. Ground station melakukan navigasi dengan cara melihat monitor ground station yang menampilkan gambar dari kamera yang terpasang pada pesawat secara real time. Informasi navigasi seperti posisi, ketinggian, kecepatan, arah mata angin dan sisa bahan bakar juga ditampilkan pada layar ground station berbasis on screen sebagai dasar pertimbangan untuk melakukan kendali.

Tujuan utama penelitian ini adalah merancang sistem tele-navigasi pada pesawat tanpa awak dengan target luaran berupa pilot plan sistem tele-navigasi pada pesawat tanpa awak (Micro UAV). Dengan adanya sistem tele-navigasi yang dirancang diharapkan dapat mengatasi kelemahan dari teknologi autopilot tanpa mengurangi kemampuan pesawat tanpa awak.

\section{METODOLOGI}

\subsection{Tinjauan Pustaka}

Pembuatan sistem navigasi autopilot telah dilakukan oleh Mahista dalam penelitiannya yang berjudul "Sistem autopilot menggunakan flight control produksi Arduino" [3]. Dalam penelitiannya sistem autopilot dapat diimplementasikan pada uav quadcopter jenis x quadcopter. Penggunaan RF modul sebagai updater data pada pesawat menjadi nilai lebih dalam penelitian tersebut. Akan tetapi, penggunaan sistem autopilot pada $\mathrm{x}$ quadcopter kurang efektif karena dari hasil penelitian, penggunaan sistem autopilot dalam quadcopter hanya dapat menjangkau jarak $100 \mathrm{~m}$. ini dikarenakan konsumsi daya dari quadcopter cukup besar, sehingga untuk baterai ukuran 3 Ah hanya akan bertahan 15 menit saja. Hasil penelitian ini menjadi kontradikatif karena pada hakekatnya penggunaan sistem Autopilot adalah untuk melakukan misi untuk jarak yang cukup jauh karena pesawat tidak dapat terlihat oleh mata telanjang.

Pembuatan sistem navigasi autopilot juga telah dilakukan sebelumnya oleh Christiansen pada tahun 2004 [1]. Sistem autopilot yang dikembangkan adalah aplikasi untuk pesawat uav kecil. Dalam penelitiannya sistem autopilot dikombinasikan dengan sistem remote sebagai launcer pesawat. Kombinasi remote dan sistem autopilot yang dapat diaktifkan atau dinon-aktifkan adalah nilai lebih dari penelitian yang dilakukannya. Akan tetapi, penggunaan sistem autopilot ini kurang efektif karena dari hasil penelitian yang telah dilakukan, sistem autopilot hanya dapat digunakan jika posisi pesawat sudah diatas dan tidak menemui halangan. Dengan demikian sistem autopilot seperti ini tidak dapat digunakan untuk pesawat tanpa awak yang memiliki ketinggian rendah. Dibalik kekurangan itu, pesawat uav kecil ini memiliki jangkauan yang cukup jauh karena jenis pesawat ini menggunakan motor tunggal sehingga lebih hemat dalam konsumsi daya.

FPV(First Person View) adalah sebuah sistem yang seolah olah pengendali berada pada pesawat yang dikendalikan [2]. Aplikasi FPV dalam pesawat tanpa awak digunakan untuk memantau apakah gambar citra yang akan diambil sudah benar atau belum. Dalam penelitian ini didapatkan informasi bahwa pengambilan gambar dengan melihat pandu dari FPV akan menghasilkan gambar sesuai dengan yang dicari. Sistem FPV yang digunakan terdiri dari kamera yang terhubung dengan video sender yang selanjutnya dikirim ke ground station. Jenis pesawat yang digunakan dalam penelitiannya adalah pesawat uav kecil dengan hasil gambar cukup baik.

Dari Telaah pustaka yang dilakukan dapat disimpulkan bahwa algoritma autopilot murni tidak dapat diterapkan pada pesawat tanpa awak, algoritma autopilot tersebut belum dapat membedakan penghalang yang menghadangnya, untuk mengatasi kekurangan autopilot dapat digunakan sistem FPV untuk mendefinisikan apakah yang didepan pesawat terdapat halangan atau tidak. Dengan menggabungkan sistem FPV dengan data sistem autopilot yang dikembangkan secara On Screen maka akan didapatkan sistem Tele-navigasi pada pesawat tanpa awak.

\subsection{Tujuan Penelitian}

Membuat rancangan untuk mengatasi kekurangan algoritma autopilot yang diterapkan pada UAV, yaitu autopilot yang belum membedakan penghalang didepannya. Membuat rancangan sistem gabungan FTV dengan data system autopilot dan dikembangkan secara On Screen dalam sistem Tele-Navigasi. 


\subsection{Metode Penelitian}

\subsubsection{Rancangan Pesawat Tanpa Awak (Mikro UAV)}

Pesawat yang dirancang adalah pesawat berjenis flying wing dengan penggerak sebuah motor brushless dengan bahan foam board. Pesawat ini digunakan untuk uji lapangan untuk mengetahui pengaruh akselerasi, ketiinggian dan angin terhadap performa sistem tele-navigasi yang dirancang. Flying wing memiliki struktur sepasang wing aerofoil tanpa adanya tail pada pesawat. Sistem gerak pada flying wing disebut dengan Elevon. Gambar 1 adalah plan dari pesawat flying wing yang akan dibangun. Sedangkan dimensi dari sayap flying wing dijelaskan pada Gambar 2. Untuk menjaga kestabilan gerak dari pesawat flying wing, pada sayap ditambahkan sebuah bidang yang dikenal dengan nama stabilisator. Dimensi dari stabilisator ditunjukkan pada Gambar.3.

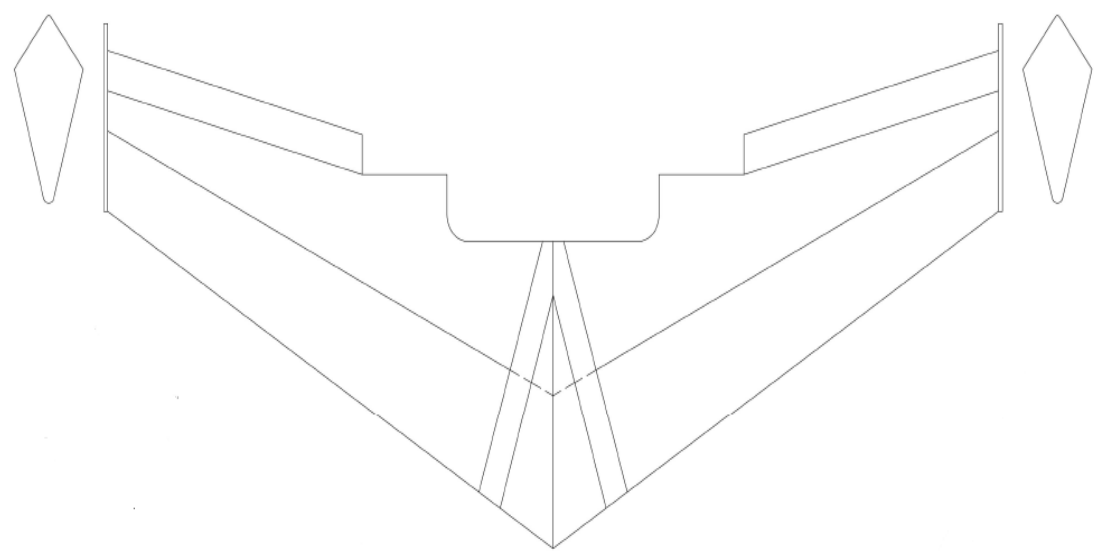

Gambar 1. Plan Flying Wing yang akan dibangun

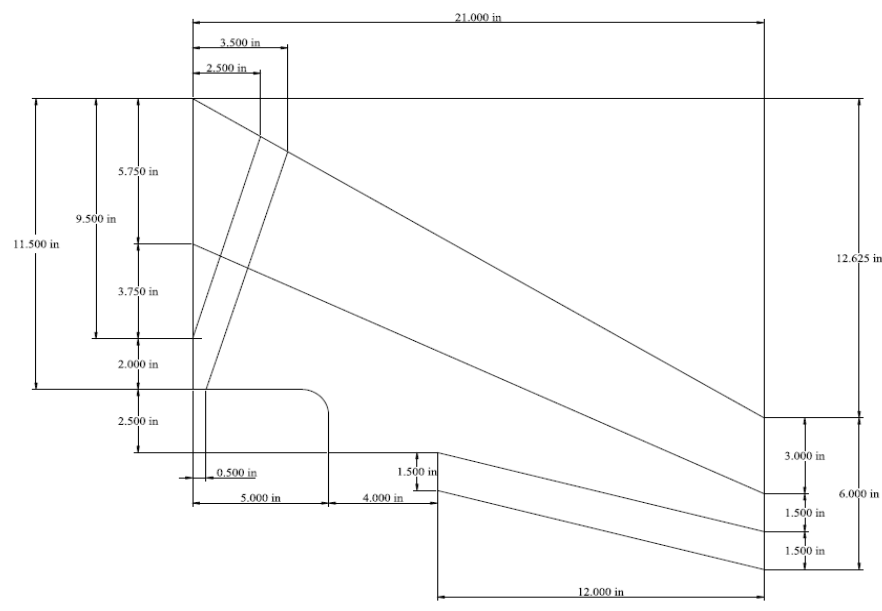

Gambar 2. Dimensi sayap flying wing

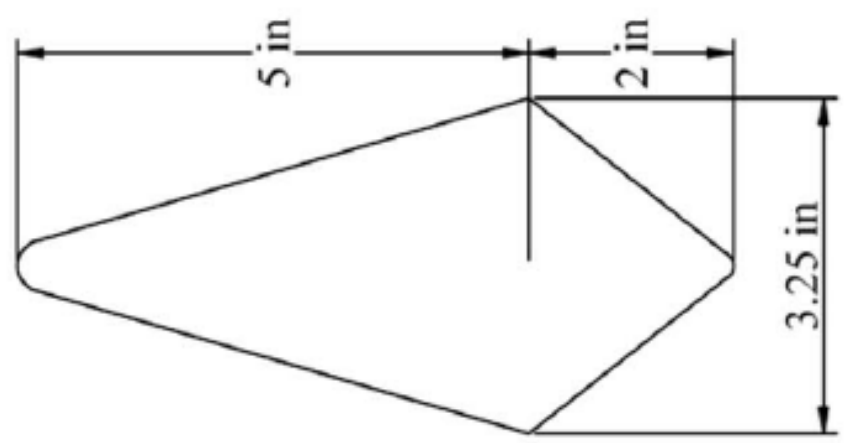

Gambar 3. Stabilisator 


\subsubsection{Rancangan Sistem Navigasi}

Desain sistem Tele-navigasi yang akan dirancang terdiri dari 2 bagian yaitu bagian remote dan ground station. Bagian remote adalah bagian yang terpasang pada pesawat tanpa awak (dikenal juga sebagai payload) sedangkan ground station adalah sistem yang memantau/ stasiun pemantauan. Skema diagram dari payload ditunjukkan oleh gambar 4 dan ground station ditunjukkan oleh gambar 5.

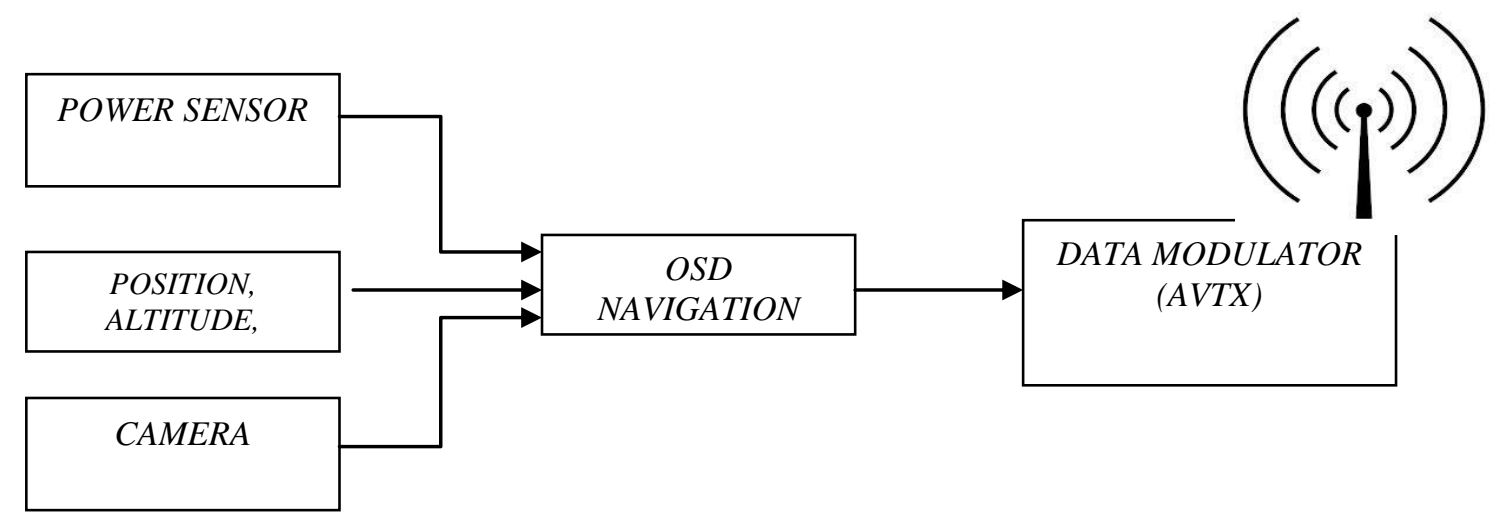

Gambar 4. Payload System

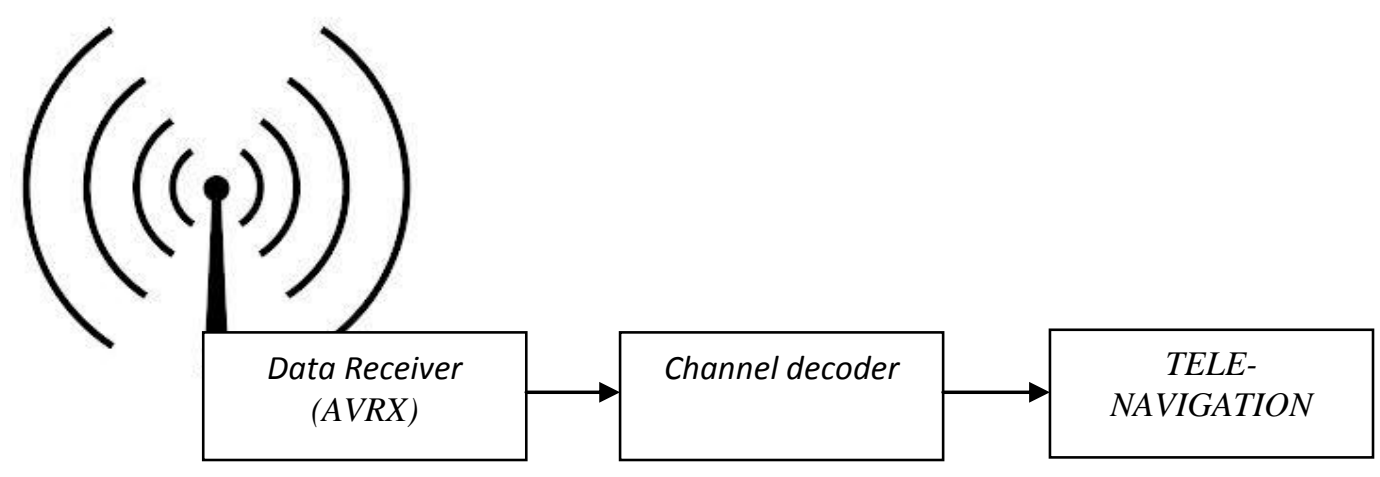

Gambar 5. Ground Station System

\section{HASIL DAN TAHAPAN PENELITIAN}

\subsection{Perancangan}

Mengumpulkan data-data dari refensi dan jurnal untuk mendesain pesawat flying wing dengan sistem yang disesuaikan kebutuhan misi dan tugasnya sesuai perencanaan.

\subsection{Pengadaan Alat dan Inslatasi}

Pembelian peralatan yang telah tersedia sebelum instalasi dilaksanakan uji fungsi dari setiap komponen. Tahap selanjutnya dilaksanakan instalasi hardware dari sistem flying wing seperti gambar 6. 


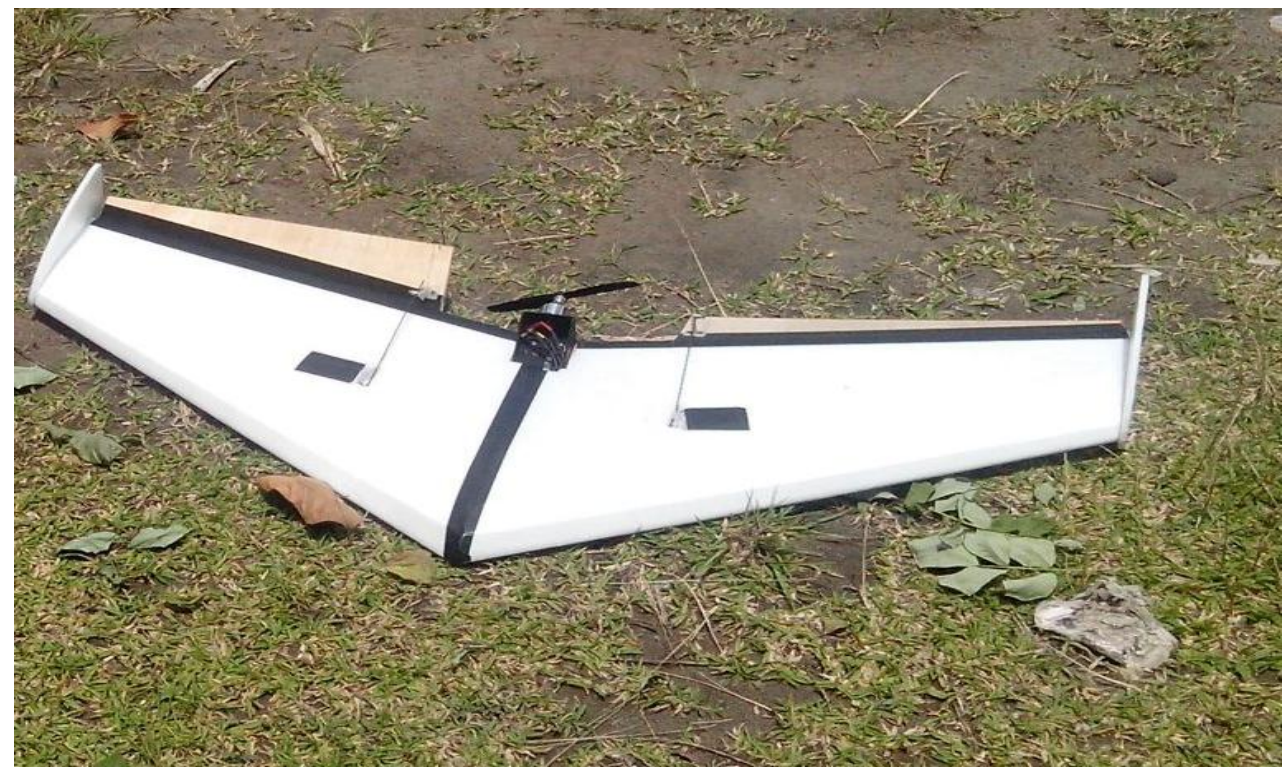

Gambar 6. Pesawat flying wing yang dibangun

\subsection{Pengujian Pesawat Model}

Instalasi hardware selesai tahap dilaksanakan pengujian secara hardware/software. Selanjutnya setelah uji laboratoris sistem dapat berfungsi dan flying wing siap uji lapangan.

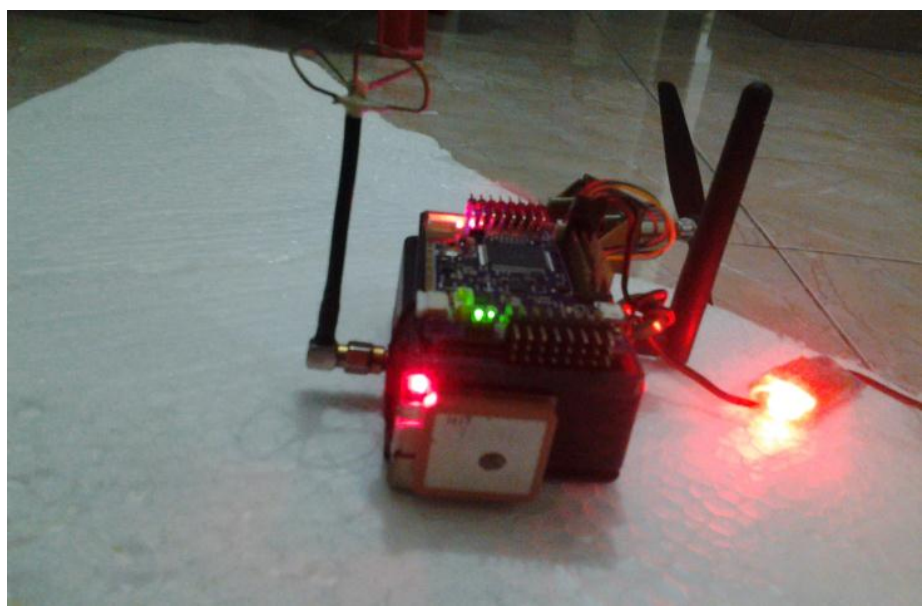

Gambar 7. Instalasi Tele-Navigasi

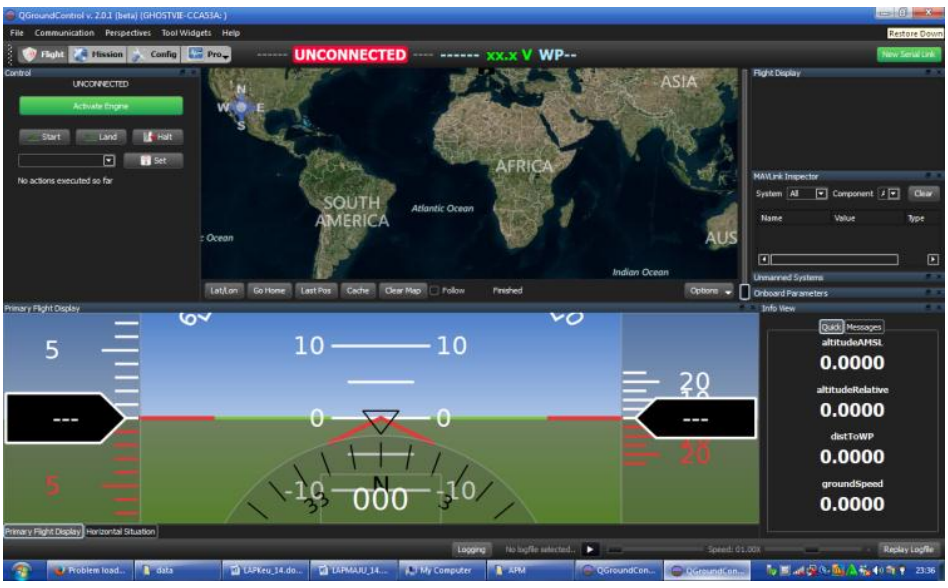

Gambar 8. Software ground control 


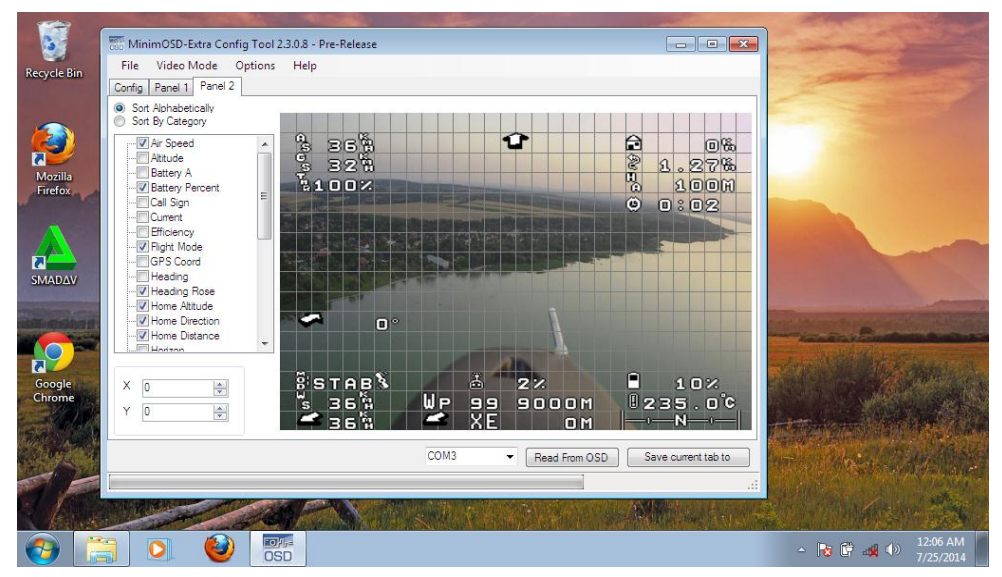

Gambar 9. Panel sistem tele-navigasi

\subsection{Pegujian Lapangan}

Pengujian lapangan dilaksanakan dengan melihat uji terbang dari pesawat flying wing yang dilengkapi Tele-Navigasi gambar 7, secara software ground control hasil rancangan dapat diamati seperti gambar 8, dan gambar 9. Uji terbang ini untuk melihat perfoma pesawat dalam pengaruh cuaca misalnya ketinggian, kecepatan dan ketahanan terbang.

\section{KESIMPULAN}

Kesimpulan yang diperoleh dari perancangan dan uji fungsi komponen Tele-Navigasi, bahwa semua komponen telah berfungsi. Untuk mendapatkan flying wing yang mampu mengirim data informasi yang diperlukan pengujian melului camera dan GPS terpasang pada pesawat.

\section{DAFTAR PUSTAKA}

[1] Christiansen, R.S., 2004."Design of an Autopilot for Small Unmanned Aeral Vehicles". Thesis. Brigham Young University

[2] Kumar,Ramesh,Srinivasan., 2011. "First Pilot Vew(FTP) Flying UAV Test Bed for Acoutic and Image Data Generation”. Symposium on Applied Aerodynamics and Design of Aerospace Vehicle (SAROD 2011)

[3] Mahista Belly., 2013."Perancangan dan Pembuatan Pesawat UAV BI-AC Quadcopter 13 dengan Sistem Autopilot". Skripsi. Sekolah Tinggi Teknologi Adisutjipto 